\title{
EFFECT OF BED ROUGHNESS ON HYDRAULIC JUMP CHARACTERISTICS
}

\author{
M.I. ATTIA
}

Assoc. prof. Water \& Water Strutctures Engg. Dept.

Faculty of Engg., Zagazig University, Egypt

$$
\text { تأثيـــــر خشونـــــة القــــاع على خصائص القفــزة الهيدروليكية }
$$

تم قياس خواص القفزة الهيلروليكية فى ترعة أفقية ذات جوانب ملساء رأسية, وقاع ذات أنواع مختلفة مـن

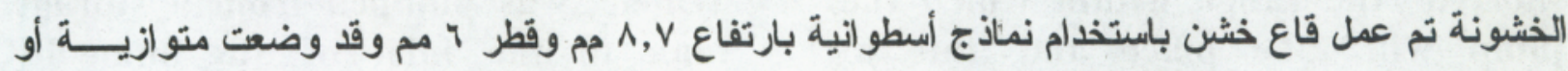

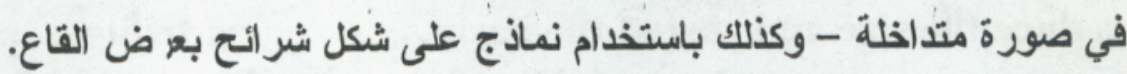

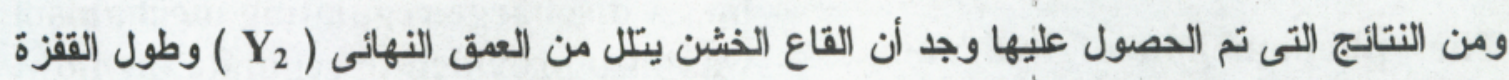

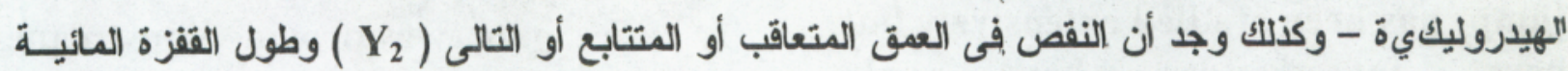

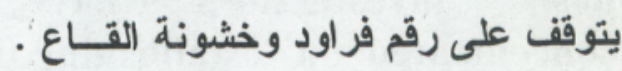

\section{ABSTRACT}

Hydraulic jump characteristics were measured over various types of artificially roughened test beds in a horizontal flume $5 \mathrm{~cm}$ bed width and smooth vertical side walls. Roughness was created using $8.7 \mathrm{~mm}$ high cylindrical pins of 6 $\mathrm{mm}$ diameter. The patterns of roughness were staggered or parallel and also using strip and spotted roughness test bed, which provided, the range of bed friction from 0.042 to 0.165 .

It was observed that the bed roughness reduces the sequent depth and length of hydraulic jump; the observed reductions were related to the Froude number and the bed roughness.

\section{INTRODUCTION}

The hydraulic engineers have been facing for a long time the problem of dissipating surplus kinetic energy of water flowing over spillways, weirs, canal drops and also through under sluices and tunnels etc. The object has been to dissipate the surplus energy as much as possible within smallest distance from hydraulic structures which overwise causes damage of the downstream bec and bank of the channel by process of continuous erosion and degradation.

There has been considerable research to study the effectiveness of various devices for dissipation of surplus energy of flowing water. One of these devices consists of using hydraulic jump for energy dissipation, which is usually confined partly of entirely to a channel reach known as stilling basin. The entire bed of the 


\section{2 M. I. Attia}

basin is completely paved to resist scouring. Practically the stilling basin is seldom designed to confine the entire length of hydraulic jump on the paved apron because such a basin would be too expensive. Consequently, accessories to control the jump are usually installed in the basin. The main purpose of such control is to shorten the range within which the jump will take place and thus to reduce the size and cost of the basin.

The phenomenon of hydraulic jump has been studied extensively but past investigators have only concentrated on establishing the flow characteristics of hydraulic jump on smooth bed. Very little information is available about the hydraulic jump characteristics over rough bed surface. Some remarkable study on hydraulic jump over rough beds was done by Hughes and flank, J.E. [5]. They used a smooth test bed, two strip roughness and three densely packed gravel test beds which provided a relative roughness ranges up to 0.9

Observations showed that boundary roughness reduces both the sequent depth and the length of hydraulic jump. Further study on the flow characteristics of hydraulic jump over bed surface was carried by Senger [9] and Govil [3].

\section{EXPERIMENTAL SET UP AND PROCEDURE}

The experimental set up consisted of an open channel rectangular flume with $5.0 \mathrm{~cm} \times 17 \mathrm{~cm}$ cross section and $5.0 \mathrm{~m}$ long. The side walls of the flume were made $o^{f}$ transparent prespex sheet. The outler of the flume was fitted with a storage tank of size $1.55 \mathrm{~m} \times 0.70 \mathrm{~m} \times 0.30 \mathrm{~m}$ which was further connected to a measuring tank. The inlet of the flume was made with a pipe of diameter $\mathbf{2 . 5 4}$ cm connected from a storage tank. Water was pumped from a storage tank to the inlet of the flume by centrifugal pump with capacity of 1 hp. A discharge regulating mechanism was also provided to regulate the flow. A sluice gate was provided upstream and a plain vertical gate was usec downstream for the formation of the hydraulic jump in the middle of the flume.

\section{ROUGHNESS ELEMENTS}

Following types of the roughness elements were used.

Spotted Roughnes Elements :

(a) A series of circular staggered elements $1 \mathrm{~mm}$ and height $1.45 \mathrm{~mm}$.

(b) A series of circular elements of diameter $5 \mathrm{~mm}$ and height $1.85 \mathrm{mn}$ placed at equal distance along the direction of the flow.

\section{$\underline{\text { Right angled strip element }}$}

Right angled strip elements of height $5 \mathrm{~mm}$ with sloping side in the upstream direction and clear spacing of $2 \mathrm{~cm}, 1 \mathrm{~cm}$ and $0.5 \mathrm{~cm}$.

\section{Cylindrical Roughness:}

Solid cylindrical pins of $6 \mathrm{~mm}$ diameter and $8.7 \mathrm{~mm}$ height made of plastic were to produce roughness on 
the bed of the channel on the downstream of the gate. The pins were so arranged on the bed as to produce staggered as well as parallel roughness elements.In all cases the strip as well as cylindrical roughness elements were inserted on the rubber ped at the downstream of the gate up to a considerable length of flume Fig.1.

Four quantities were measured to describe each hydraulic jump.

(a) The flume discharge, $Q$ varied between $0.454 \mathrm{l} / \mathrm{s}$ and $3.0 \mathrm{l} / \mathrm{s}$.

(b) The initial depth $Y_{1}$ was determined from point gauge measurements just upstream from the leading edge of the surface roller. It varied between $0.945 \mathrm{~cm}$ and $2.40 \mathrm{~cm}$.

(c) Sequent depth $\mathrm{Y}_{2}$ was determined from point gauge measurements, which varied from $3.16 \mathrm{~cm}$. to $7.42 \mathrm{~cm}$.

(d) Jump length $\mathrm{Lj}$ was measured from the leading edge of the jump to a point just downstream from the top roller of the jump. The length of the hydraulic jump varied from $6 \mathrm{~cm}$ to $20 \mathrm{~cm}$.

The range of Reynolds number and that of Froude number were between $1.49 \times 10^{4}$ to 6.9 $X 10^{4}$ and 2.15 to 5.73 , respectively.

\section{ANALYSIS OF DATA}

The Darcy - Weisbach bed friction factor $f_{b}$ can be related to Manning 's coefficient of bed roughness $n_{b}$ for bed only as. $n_{b}=8 g /\left(R^{1 / 6} / n_{b}\right)^{2}$

The coefficient of roughness for bed only, was calculated from the estimated readings of hydraulic radius for bed $R_{b}$ and channel longitudinal slope $\mathrm{S}$ using Einstein - Barbarossa method (Appendix B) separating the effects of side and bed roughness. Thus a series of values for $f_{b}$ were obtained for different conditions of flow. The ratio between the sequent depth and the initial depth $\left(\mathrm{Y}_{2} / \mathrm{Y}_{1}\right)$ was plotted for corresponding values of Froude number $\left(F_{1}\right)$ with $f_{b}$ as third parameter, Fig.2. A distinct trend in the relationship was observed. The slope of the best fit line between $\left(\mathrm{Y}_{2}\right)$ $\left.Y_{1}\right)$ and $F_{1}$ that is $m$, was plotted against corresphonding values of $f_{b}$ Fig.3, which provided the relationship

$m=1.297-2.407 f_{b}$

Using the above mentioned expression for $\mathrm{m}$, a relationship between $Y_{2} / Y_{1}$ and $F_{1}$ is obtained as follows.

$$
\begin{aligned}
Y_{2} / Y_{1}= & \left(1.297-2.407 f_{b}\right) F_{1}+ \\
& 4.814 f_{b}-0.224
\end{aligned}
$$

Equation 3 can be used to determine the values of $\mathrm{Y}_{2} / \mathrm{Y}_{1}$ for any bed friction factor $f_{b}$ at given Froude number, $F_{1}$. Considering no bed friction (i.e. $f_{b}=0$ ), Eqn. 3 reduces to. $\mathrm{Y}_{2} / \mathrm{Y}_{1}=\mathbf{1 . 2 9 7} \mathrm{F}_{1}-\mathbf{0 . 2 2 4}$

This equation does not match with the theoretically derived Belenger's equation. 


$$
Y_{2} / Y_{1}=1 / 2\left(\sqrt{1+8 F_{1}^{2}}-1\right)
$$

Which can be approximated to $\mathrm{Y}_{2} / \mathrm{Y}_{1}=\mathbf{1 . 4 0 4} \mathrm{F}_{1}-\mathbf{0 . 5 0 0}$

This equation was derived considering no bed friction, however in an experimental work, there will always be some friction at the bed. The maximum deviation of Eqn.4 with Belenger's equation is $+6 \%$ only.

The fact that the resistance to the flow increases in channels with increase of Froude number has been studied by earlier investigators [10]. The trend is verified in the present paper also.

\section{CONCLUSIONS}

1. The slope of the trend line using test data was obtained as $\mathbf{1 . 2 9 7}$ which is close to the slope vaule as obtained by theoretical equation given by Belanger.

2. The graphical representation of the data collected by using different roughness test beds shows that the effect of change of concentration (spacing between two elements) is more on the bed roughness than the change in pattern (parallel or staggered) of fixing the roughness elements.

3. The data for rough bed lie close to the line for smooth bed as the Froude number decreases. Theoretically there is a jump formation when $F_{1}$ is greater than 1. But practically it is not possible to predict the jump formation for
$F_{1}$ less than 2 because jump is very weak Hence in the graphica representation, the lines for different roughness test bed and smooth bed appear to be meeting at $\mathrm{F}_{1}=2$.

4. Comparison of the data trends from one curve to the next shows that the reduction in ratio of sequent to initial depth becomes very pronounced as bed roughness increases. As the bed roughness increases the trend line falls progressively further below the smooth boundary curve. The observed reduction was found to be the related to both the initial Froude number and bed roughness.

5. The length of jump, is reduced as the bed roughness increases, for all : Froude number. The relationship between the slope of trend lines $(\mathrm{m})$ and bed friction factor $f_{b}$ could be represented by . $m=1.297-2.407 f_{b}$

6. The relationship between $Y_{2} / Y_{1}, F_{1}$ and $f_{b}$ is found as

$$
\begin{gathered}
Y_{2} / Y_{1}=\left(1.297-2.407 f_{b}\right) F_{1}+ \\
4.814 f_{b}-0.224
\end{gathered}
$$

7. The line representing the relationship between $\mathrm{Y}_{2} / \mathrm{Y}_{1}$ and $F_{1}$ for $5 \mathrm{~mm}$ high right 
Mansoura Engineering Journal, (MEJ), Vol. 30, No. 1, March 2005.

C. 5

angles strip roughness element

with clear spacing of $0.5 \mathrm{~cm}$

overlaps the line representing

the relationship between $\mathrm{Y}_{2}$ /

$Y_{1}$ and $F_{1}$ for $8.7 \mathrm{~mm}$ high

pins.

(a) $2.0 \mathrm{~cm} \mathrm{C} / \mathrm{C}$ (staggered) It shows that the roughness produced by $5 \mathrm{~mm}$ high right angled strip roughness element is equivalent to the roughness produced by $8.7 \mathrm{~mm}$ high pins (a) $2 \mathrm{~cm} \mathrm{C/C}$ (staggered).

8. Field data are not available to the outhor to verify their experimental results.

\section{REFERENCES}

1. Bayazit, M., Jl.Of Hyd. Div. Research, 142 (1976).

2. Bonald, W. Knight and J. Alsadair Mac. Donald, Proc. A.S.C.E. Jl. Of Hyd. Div. (1979).

3. Hseich, W. Shen., Proc. A.S.C.E., J1 of Hyd. Div. (1973).

4. Hughes, W.C. and Flack, J.E., Proc. A.S.C.E., Jl. Of Hyd. Div. $10: 12$ (1984).

5. Rouse Hunter, Proc. A.S.C.E. Jl. Of Hyde. Div. 8 (1965).
6. Raju, K.G. and Garde, R.J., Proc A.S.C.E., Jour. Of Hyd. Div. 96: No. HY 3 (1970).

7. Sayre, W.W. and Albertsion, A.L., Tran. A.S.C.E., (1963).

8. Chow, V.T., "Open Channel Hydraulics," Mc Grew Hill Book Company, Singapore, (1956), 204-205 .

9. Lo' krou, V.P. and, H.W., "Analysis of the Characteristios of Flow in Sudden Expansion by Similarity Approach, Journal of Hydraulic Research( 21), No.2, 1985, PP. 119-133.

10. Forster, John, W., and Skrinde, Raymond, A., "Control of the Hydraulic jump by sills, proceeding of the ASCB, Vol,80, HYB, 1950.

\section{APPENDIX - A}

Bed friction factor $f_{b}$ for height angled strip roughness test bed with clear spacing of $1.0 \mathrm{~cm}$.

The following values for this case are given as follows:

Composite roughness, $\mathrm{n}=\mathbf{0 . 0 1 6 2}$

Depth flow, $\mathrm{y} \quad=2.30 \times 10^{-2} \mathrm{~m}$

Hydraulic radius,$R_{h}=1.425 \times 10^{-2} \mathrm{~m}$

Side wall roughness, $\mathrm{n}_{\mathrm{w}}=\mathbf{1 . 0 1 0}$ 
Using the Einsten and Barbarossa's method,

$$
R_{w}=\left(n_{w} R_{h}{ }^{2 / 3} / n\right)^{2 / 3}
$$

Substituting the previous values, into the foregoing egn:

$R_{w}=\left[0.1 \times\left(1.425 \times 10^{-2}\right)^{2 / 3} / 0.0162\right]^{3 / 2}$ $=6.94 \times 10^{-3} \mathrm{~m}$

But, $A_{w}=R_{w} \times 2 y=3.19 \times 10^{-4} \mathrm{~m}^{2}$ Therefore, ${ }_{b}=A-A_{w}=1.405 \times 10^{-3} \mathrm{~m}^{2}$ Hence, $R_{b}=A_{b} / B=0.0187 \mathrm{~m}$

Now using the relation, $\mathbf{n}_{\mathrm{b}}=\mathbf{n}_{\mathrm{w}}\left(\mathbf{R}_{\mathrm{b}} / \mathbf{R}_{\mathrm{w}}\right)^{2 / 3}=$ $0.010\left(0.0187 / 6.94 \times 10^{-3}\right)^{2 / 3}=0.0193$

But, $C_{b}=R_{b}{ }^{1 / 6} / n_{b}=26.62$

Hence,

$$
f_{b}=8 g / C_{b}^{2}=0.110
$$

\section{APPENDIX - B}

To check the type of boundary surface, the following data are chosen for this purpose.

Flow rate, $Q=0.054 \times 10^{-3} \mathrm{~m}^{3} / \mathrm{sec}$.

Flow velocity, $\mathrm{V}=26.3 \times 10^{-2} \mathrm{~m} / \mathrm{sec}$.

Longitudinal slope, $\mathrm{S}=5.235 \times 10^{-3}$

Hydraulic radius, $R_{h}=1.425 \times 10^{-2} \mathrm{~m}$

Shear velocity, $u_{*}=\sqrt{\mathrm{g} . \mathrm{R}_{\mathrm{h} .} \mathrm{S}}$ $=\sqrt{9.81 \times 1.425 \times 10^{-2} \times 5.235 \times 10^{-3}}=$ 0.0270

Thickness of laminar sublayer

$$
\delta=\frac{11.6 \gamma}{\mathrm{u}^{*}}=\frac{11.6 \times 10^{-6}}{0.0270}=
$$

$$
4.2962 \times 10^{-4} \mathrm{~m}
$$

Bed friction factor, $f_{b}=\mathbf{0 . 1 1 0}$ from Appedix A .

Using well known Colebrook and White equation Raju [ 6]

$$
\begin{aligned}
& \sqrt{f}=1.14-2 \log \left(\frac{k s}{4 R_{h}}+\frac{21.25}{R e^{.090}}\right) \\
& \begin{aligned}
\operatorname{Re}= & V \times 4 \times R_{h} / v \\
& =\left(26.3 \times 10^{-2} \times 4 \times 1.425 \times 10^{-}\right.
\end{aligned} \\
& \left.2 / 1 \times 10^{-6}\right)=1.94 \times 10^{4}
\end{aligned}
$$$$
\text { or } \frac{1}{\sqrt{0.110}}=1.14-2 \log _{4 \times 1.25 \times 10^{2}}
$$$$
\left.+21.25\left(1.49 \times 10^{4}\right){ }^{-9}\right]
$$

or $\quad k s=6.369 \times 10^{-3} \mathrm{~m}$

$$
\text { Now, } \frac{\mathrm{ks}}{\delta^{1}}=\frac{6.369 \times 10^{-3}}{4.2962 \times 10^{-\mathrm{F}}} \mathbf{1 4 . 8 2 4}>\mathbf{6}
$$

Hence, the surface is ydrodynamically rough. Alternatively,

$$
\begin{aligned}
& \frac{u^{*} X \mathrm{ks}}{v}=\frac{0.0270 \times 6.369 \times 10^{-3}}{1 \times 10^{6}} \\
& =171.963>100
\end{aligned}
$$

(hydrodynamically rough) 


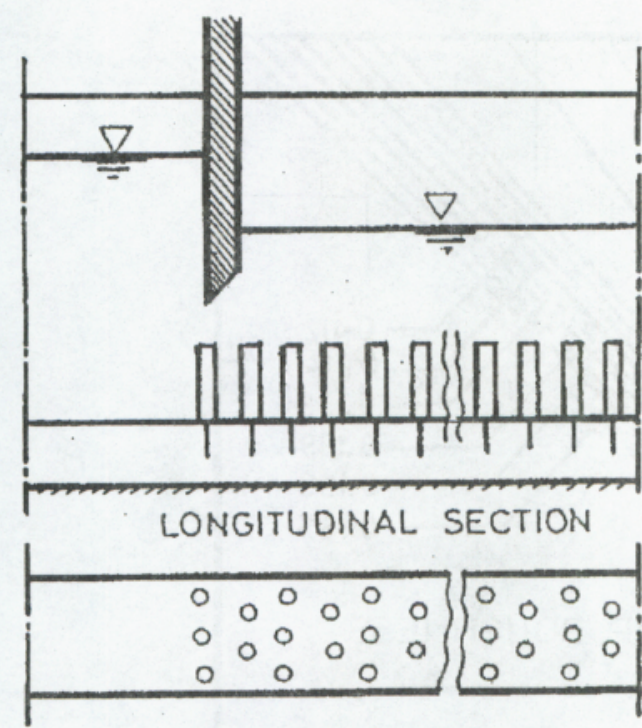

STAGGERED PIN ROUGHNESS
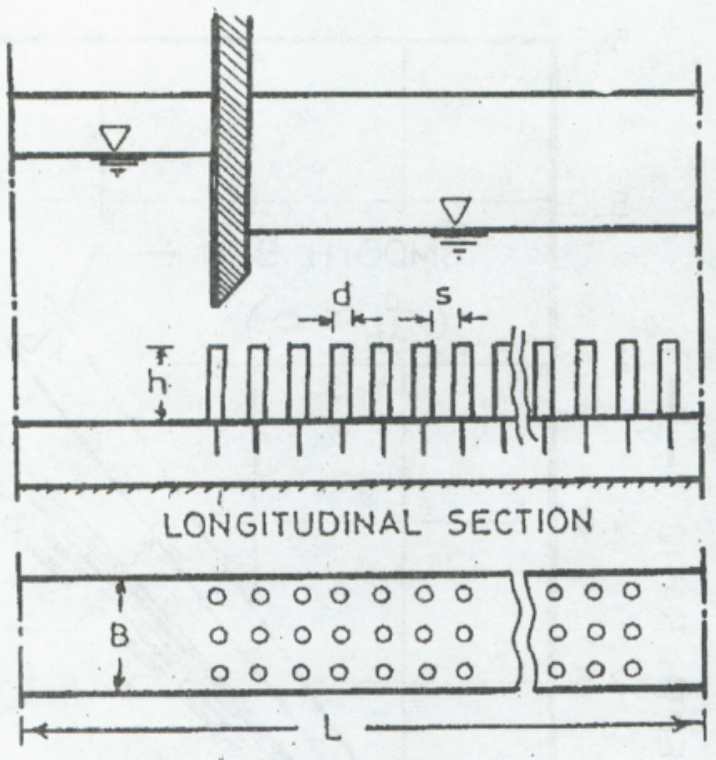

PARALLEL PIN ROUGHNESS

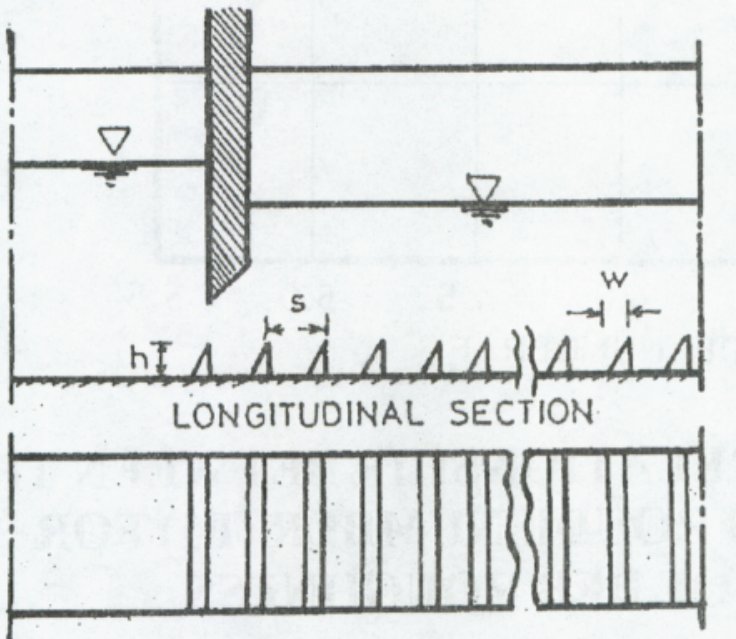

NOTATION

$h=$ HEIGHT OF ROUGHNESS

$s=$ SPACING

$\mathrm{d}=$ DIAMETER

$w=$ WIOTH

$B=$ WIDTH OF FLUME

$\mathrm{L}=$ LENGTH OF FLUME

PARALLEL STRIP ROUGHNESS

FIG.1 - ARRANGEMENT OF ROUGHNESS ELEMENTS 
$\begin{array}{ll}\text { C. } 8 & \text { M. I. Attia }\end{array}$

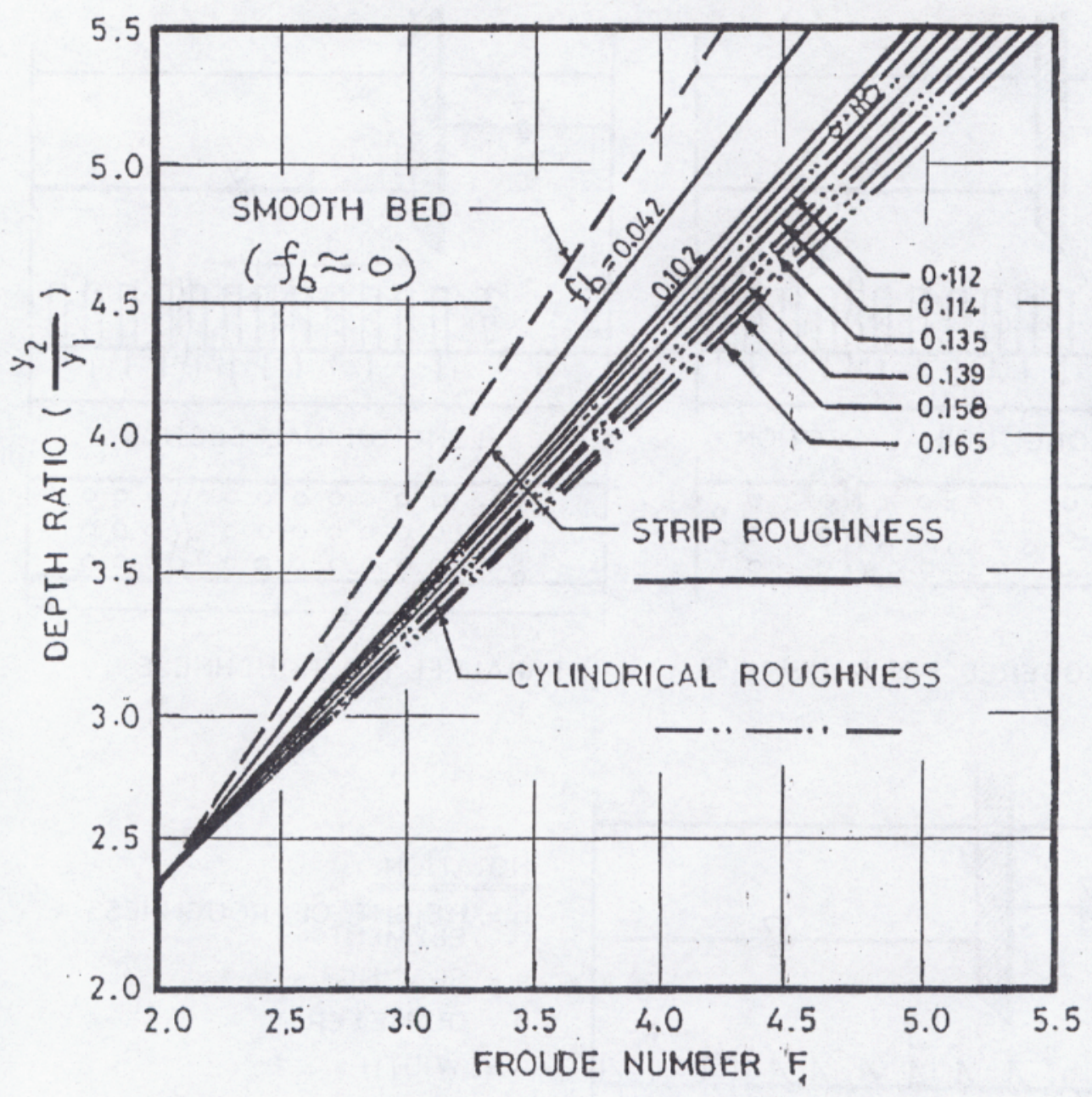

FIG.2 PLOT SHOWING THE RELATIONSHIP BETWEEN THE DEPTH RATIO $\left(y_{2} / y_{1}\right)$ AND FROUDE NUMBER (F1) FOR DIFFERENT TYPES OF DEB ROUGHNESS 


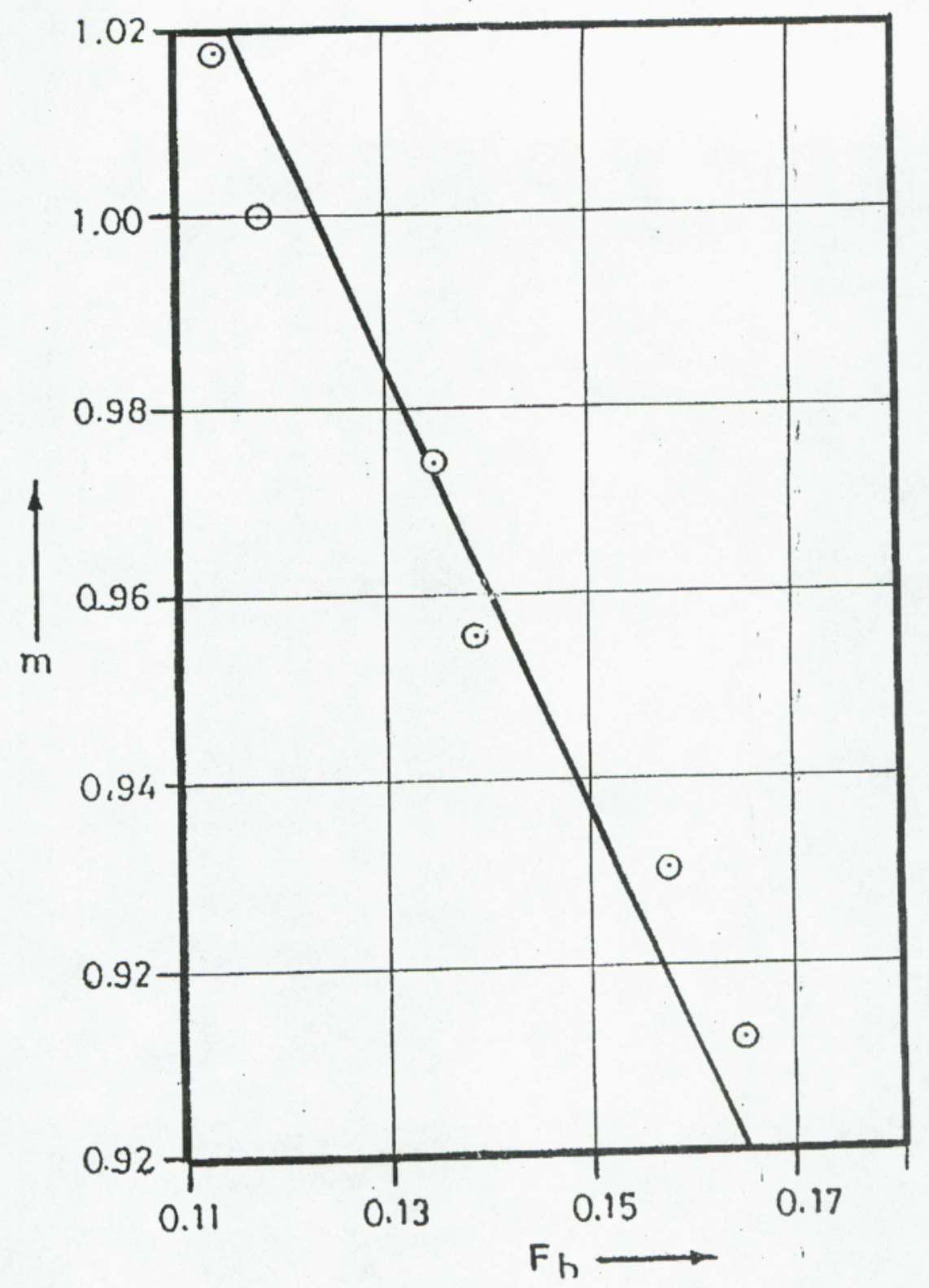

FIG.3 PLOT SHOWING THE RELATIONSHIP BETWEEN SLOPE OF TREND LINE $(m)$ AND DEB FRICTION FACTOR $\left(F_{b}\right)$ 